Erratum to:

\title{
Variation in aggressiveness of Plasmopara halstedii (sunflower downy mildew).
}

Sakr N. (2009)

J Plant Dis Protect 116, 247-251.

The names of the authors should be:

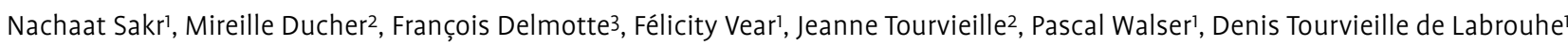

1 INRA-UMR 1095-Clermont-Ferrand, France

2 INRA-UMR 1095, Aubière, France

3 INRA-UMR 1065, Villenave d'Ornon cedex, France 